Japanese Journal of Applied Physics, 21 (7) (1982) 1032-1036

\title{
Laser-Induced Fluorescence of Oil Colours and Its Application to the I dentification of Pigments in Oil Paintings
}

Tadaki Miyoshi, Motoji Ikeya, Shuichi Kinoshita ${ }^{1}$ and Takashi Kushida ${ }^{1}$

Technical College, Yamaguchi U niversity, Tokiwadai, U be, Yamaguchi 755

${ }^{1}$ D epartment of Physics, O saka U niversity, Toyonaka, O saka 560

(Received December 5, 1981; accepted April 17, 1982)

We have investigated the spectra and decay characteristics of the fluorescence produced in oil colours under pulsed laser excitation. It was found possible to identify pigments in paintings by measuring the fluorescence, and it is suggested that the laser-induced fluorescence method can be used to detect forgeries in oil paintings. 


\section{$\S 1$. Introduction}

Many scientific methods have been used for dating, identification of materials in archaeology ${ }^{1)}$ and detection of forgeries in fine art. ${ }^{2)}$ Forged oil paintings can be detected by investigating the pigments used in the oil colours, because different pigments were used at different times in history. In destructive methods, a very small amount of oil colour is scraped from the painting, and examined by microscopy, X-ray analysis, neutron activation analysis, mass spectrometry, etc, ${ }^{2)}$ while X-ray photography, infrared reflection and ultraviolet (UV) analysis have been used as nondestructive methods. Nondestructive methods are naturally desirable in preserving valuable art objects.

In recent years, laser-induced fluorescence has been used to investigate the physical properties of materials. Previously, we studied the fluorescence associated with defects in $\mathrm{CaCO}_{3}$ using an $\mathrm{N}_{2}$ laser, and proposed a new dating method for stalactite by detecting defects produced by natural radiation. ${ }^{3)}$ Semiconductors and organic dyes show characteristic fluorescence under intense excitation. ${ }^{4,5}$ Many pigments used in oil colours are composed of semiconductors and organic dyes. We believe it possible to identify the pigments in most oil colours by measuring the fluorescence under laser excitation. Measurement of the decay characteristics combined with spectral results is expected to provide useful clues for identifying pigments, because different decay characteristics combined with spectral results is expected to provide useful clues for identifying pigments, because different decay characteristics have been observed in different materials.

In this report, we propose a new nondestructive method (the laser-induced fluorescence method) in which we use pulsed light from lasers and measure the fluorescence of oil colours. Oil colours have different spectra and decay characteristics of fluorescence even in the same colour groups, enabling us to identify the pigments used.

As far as we know, this is the first report on the application of laser-induced fluorescence to the identification of pigments in oil colours. Although the laser has been used for identifying pigments, in the laser microspectral analyzer, ${ }^{6}$ this is a destructive method. In this analyzer, the laser is used to evaporate a certain microsection of the painting, and the pigment is then identified by analyzing the spectra of the elements 
composing it. In the laser-induced fluorescence method, the analysis is based on the spectral bands of compounds instead of elements. Thus, the fluorescence method can be used on pigments made from both inorganic and organic compounds.

\section{§2. Experimental Procedure}

Most of the oil colours used were obtained from Matsuda Ltd. Samples were prepared by painting thin $\mathrm{Al}$ plates, and the fluorescence spectra were measured using a pulsed $\mathrm{N}_{2}$ laser $(\mathrm{h} v=3.68 \mathrm{eV}, \lambda=337.1 \mathrm{~nm}$, pulse duration $=5 \mathrm{~ns}$, repetition rate $=4$ $\mathrm{Hz})$. Light from the laser was focused on the sample by a quartz lens, the area of the laser spot being about $3 \mathrm{~mm}^{2}$. The peak intensity of light on the sample was about 100 $\mathrm{kW} / \mathrm{cm}^{2}$. Discolouration was not observed even in pigments made from organic compounds under this level of excitation intensity.

The laser beam was incident on the sample at an angle of about $45^{\circ}$. Fluorescence was observed at $90^{\circ}$ to the incident beam and was focused on to the entrance slit of a 50 cm monochromator (Oyo-Bunko ASI-50S) by a glass lens. Fluorescence spectra were obtained by the monochromator, a photomultiplier (Hamamatsu TV R955), a boxcar integrator and a recorder. As the peak intensity of the fluorescence was high, measurement was not affected by room light, and a darkroom was not needed. When an ordinary Hg lamp was used as a UV light source, stray light from the Hg lamp affected the spectra of fluorescence from oil colours even in a dark-room.

The decay characteristics of the fluorescence were measured in various oil colours using a mode-locked $\mathrm{Ar}^{+}$ion laser $(\mathrm{h} v=2.41 \mathrm{eV}, \lambda=514.5 \mathrm{~nm}$, pulse duration $=150 \mathrm{ps}$, repetition rate $=80 \mathrm{MHz}$ ). The peak intensity of light on the sample was about $1 \mathrm{~kW} / \mathrm{cm}^{2}$. Since the excitation intensity was low, no discolouration was observed. The transient behaviour of the fluorescence was measured using a highly-sensitive time-correlated single photon counting method. ${ }^{7)}$ The time behaviour of the fluorescence was also measured by using a mode-locked Nd-YAG laser and an optical Kerr shutter. However, discolouration was observed during measurement. As this measuring system is less sensitive, a higher level of excitation (about $10 \mathrm{MW} / \mathrm{cm}^{2}$ ) is necessary. 
Fluorescence was observed in most of the forty or so oil colours examined. Figure 1 shows the fluorescence spectra of some typical oil colours. The peak intensities are normalized. Different fluorescence spectra (spectral shape, peak wavelength and peak intensity) are observed. Pigments consisting of zinc white $(\mathrm{ZnO})$, cadmium yellow (CdS) and cadmium red $(\mathrm{Cd}(\mathrm{S}, \mathrm{Se}))$ are II-VI semiconductors. Figure 2 shows the fluorescence spectra of single crystals of $\mathrm{ZnO}, \mathrm{CdS}$ and $\mathrm{Cd}(\mathrm{S}, \mathrm{Se})$. While single crystals have a narrower spectral width than oil colours, the spectral shapes of single crystals are similar to those of oil colours. This confirms that the fluorescence spectra in Fig. 1 are due to pigments and not to impurities.

Some commonly used white colours are listed in Table I. Zinc white shows intense fluorescence with relatively narrow spectral width, as shown in Fig. 1. The fluorescence spectrum of titanium white is similar to that of zinc white, because $\mathrm{TiO}_{2}$ (titanium white) is manufactured with the addition of small amount of $\mathrm{ZnO}$ (zinc white). The fluorescence of $\mathrm{TiO}_{2}$ is very weak and is covered by that of the $\mathrm{ZnO}$. No fluorescence is observed in lead white.

Figure 3 shows the fluorescence spectra of yellow colours with different pigments. The peak wavelength and peak intensity of the fluorescence are shown in Table II. Figure 4 shows the fluorescence spectra of the red colours listed in Table III. Different fluorescence spectra are observed even in the same colour groups. Pigments made from semiconductors (zinc white, cadmium yellow and cadmium red) show intense fluorescence and narrow spectral widths. On the other hand, pigments made from organic compounds (permanent yellow, scarlet lake, vermilion (tint) and carmine lake) show broad spectral widths.

Figure 5 shows the time behaviour of the fluorescence of red colours. The decay characteristics observed are different for different pigments. Pigments made from semiconductors show slow decay, while organic compounds show fast decay. Figure 6 shows the time behaviour of the fluorescence of carmine lake made by different manufacturers. Almost the same decay characteristics are observed. The fluorescence spectra were also measured and almost the same spectra were observed. The time behaviour and spectra of fluorescence were measured for other red pigments made by different manufacturers. The fluorescence characteristics of most pigments were found to 
be independent of the manufacturer.

The fluorescence spectra were also measured with mixed colours. It was found possible to observe the characteristic fluorescence of oil colours when one of the pigments emits intense fluorescence, or when the spectral bands of the flourescence are not close to each other. The spectral shapes were almost the same as those of individual oil colours in this case.

\section{$\S 4$. Application to Identification of Pigments and Possibility of Detecting Forgeries}

We can identify the pigments of oil colours, because oil colours have different spectra and decay characteristics of fluorescence even in the same colour groups; and different pigments have been used in different times in history. For example, lead white has been used from pre-Roman times, while zinc white has only been used from the mid-19th century and titanium white from the 20th century. As mentioned in $\S 3$, zinc white shows intense fluorescence, while no fluorescence is detected in lead white (Table I). Therefore, we can use the fluorescence of zinc white as an indicator of paintings forged after the mid-19th century.

It could be argued that the fluorescence method would not detect a forgery done by a careful forger who avoided using zinc white. However, zinc white (or $\mathrm{ZnO}$ ) is usually contained in modern oil colours to regulate the tone, while it is never present in old oil colours manufactured before the mid-19th century. ${ }^{2)}$ In fact, we observed the fluorescence of $\mathrm{ZnO}$ in the following oil colours: titanium white, cobalt violet light (tint) (organic compounds), cobalt blue (tint) $\left(=\right.$ ultramarine $\left.\left(2\left(\mathrm{Na}_{2} \mathrm{O} \cdot \mathrm{Al}_{2} \mathrm{O}_{3} \cdot \mathrm{SiO}_{2}\right) \cdot \mathrm{Na}_{2} \mathrm{~S}_{2}\right)\right)$, emerald green (shade) (organic compounds), cobalt green pale $(\mathrm{CoO} \cdot \mathrm{ZnO} \cdot \mathrm{MgO})$, lemon yellow $\left(\mathrm{BaCrO}_{4}\right)$, citron yellow $\left(\mathrm{ZnCrO}_{4} \cdot \mathrm{K}_{2} \mathrm{CrO}_{4} \cdot \mathrm{ZnO}\right)$ and permanent yellow (organic compounds). 'Tint' and 'shade' are composed of different pigments, but have a tone similar to that of oil colours with genuine pigments. Since the fluorescence of $\mathrm{ZnO}$ is intense, we can detect $1 \%$ of zinc white in mixed colours.

The fluorescence method was used to identify the pigments of oil colours painted on a canvas about four years ago by an amateur artist. Figure 7 shows the fluorescence spectrum of a yellow part of painting. Two spectral bands are observed at $380 \mathrm{~nm}$ and $540 \mathrm{~nm}$. Since the $380 \mathrm{~nm}$ band is very close to curve 1 in Fig. 1, it is ascribed to $\mathrm{ZnO}$. 
Thus, we conclude that the yellow part contains zinc white. The yellow colours are probably chrome yellow citron, because the $540 \mathrm{~nm}$ band is similar to curve 4 in Fig. 3 . The method identified the oil colours actually used by the artist, demonstrating that, the fluorescence method is actually applicable to paintings.

The advantages of the laser-induced fluorescence method are as follows:

1) It is a nondestructive method.

2) It can be used to identify pigments made from both inorganic and organic compounds. (Most methods described in $\S 1$ are not applicable to organic compounds.)

3) No darkroom is necessary when measuring the fluorescence spectra.

On the other hand, the method has the following disadvantages:

1) Laser light may discolour the pigments in a painting, since the $\mathrm{N}_{2}$ laser emits intense UV light $\left(100 \mathrm{~kW} / \mathrm{cm}^{2}\right)$. However, discolouration was not observed in our experiment because the pulse duration was very short (5 ns) and the average power was low (about $2 \mathrm{~mW} / \mathrm{cm}^{2}$ ). Higher levels of excitation (about $1 \mathrm{MW} / \mathrm{cm}^{2}$ ) causes discolouration of some oil colours, and a reduction in the fluorescence of as much as $40 \%$ is observed during measurements (lasting about 20 minutes).

2) The fluorescence of the vehicle has an effect. Oil colours contain a vehicle (linseed oil, poppy oil, etc.). The vehicle shows fluorescence of broad spectral width at about $400 \mathrm{~nm}$ with a long tail to about $600 \mathrm{~nm}$. The fluorescence intensity increases after solidification as the day goes on. The maximum intensity is observed about one month after solidification. Then, the fluorescence intensity decreases gradually as a function of time. Since most oil colours are affected by the fluorescence of the vehicle, they were tested immediately after painting on Al plates in our experiment. However, the effect of the vehicle is not expected to be negligible in measuring the fluorescence of oil colours painted on a canvas several years ago. Thus, it is necessary to measure oil colours of long wavelength (red and yellow) or oil colours with intense fluorescence (zinc white).

3) Many paintings have been retouched with modern pigments. It is therefore necessary to measure the non-retouched areas of a painting. Retouched areas can be detected by UV analysis, because the vehicle and varnish of retouched areas show intense fluorescence. $^{2)}$

4) Gradual changes in paintings over a long time may change the fluorescence. We 
measured the fluorescence of oil colours about one year after solidification. The spectral width broadens toward longer wavelength in some oil colours (cadmium yellow and cadmium red), but most oil colours show no noticeable change in their spectral shapes. The decay characteristics change in cadmium red and vermilion, but pigments made from organic compounds show little change.

\section{$\S 5$. Conclusions}

The study of the fluorescence of oil colours under laser excitation is an additional method for detecting forgeries in oil paintings. The pigments in oil colours can be identified by measuring the spectra and decay characteristics of fluorescence under pulsed laser excitation, so this method can complement other nondestructive methods in the scientific detection of forgeries. The advantage of the laser-induced fluorescence method is that it is applicable to pigments made from both inorganic and organic compounds. The method is also probably applicable to Japanese paintings, in which ink is used rather than oil colours. 
R eferences

1) M. J. Aitken: Physics and Archaeology (Clarendon Press, Oxford, 1974) 2nd ed.

2) S. J. Fleming: Authenticity in Art, The Scientific Detection of Forgery (Crane, Russak, New York, 1976).

3) T. Ugumori and M. Ikeya: Jpn. J. Appl. Phys. 19 (1980) 459.

4) $\mathrm{H} \cdot$ Haken and S. Nikitine: Excitons at High Density (Springer Verlag, Berlin and New York,1975).

5) C. N. R. Rao: Urtra-Violet and Visible Spectroscopy (Butterworth, London, 1967).

6) A. Petrakiev, A. Samov and G. Dimitrov: Jena Rev. 16 (1971) 250

7) T. Kushida ,S. Kinoshita ,H. Ohta and T. Morie: Solid State Commun. 35 (1980) 267. 


\section{Figure captions}

Fig. 1. Fluorescence spectra of oil colours under $\mathrm{N}_{2}$ laser excitation $(\lambda=337.1 \mathrm{~nm})$. Peak intensities are normalized. Intensity ratios are as follows:

1: zinc white (200),

2: cobalt blue $(0.2)$,

3: cadmium yellow (1.4),

4: chrome yellow citron $(0.1)$,

5: cadmium red (1),

6: carmine lake (0.2).

Fig. 2. Fluorescence spectra of single crystals of $\mathrm{ZnO}, \mathrm{CdS}$ and $\mathrm{CdS}_{0.7} \mathrm{Se}_{0.3}$ under $\mathrm{N}_{2}$ laser excitation. Peak intensities are normalized.

Fig. 3. Fluorescence spectra of yellow colours under $\mathrm{N}_{2}$ laser excitation. Peak intensities are normalized.

1: cadmium yellow,

2: lemon yellow,

3: citron yellow,

4: chrome yellow citron,

5: permanent yellow,

6: aureolin,

7: chrome yellow light.

Fig. 4. Fluorescence spectra of red colours under $\mathrm{N}_{2}$ laser excitation. Peak intensities are normalized.

1: cadmium red,

2: vermilion,

3: scarlet lake

4: vermilion (tint),

5: carmine lake.

The $540 \mathrm{~nm}$ peak is observed only in vermilion made by Matsuda Ltd. 'Tint' is composed of different pigments, but has a tone similar to that of oil colours with genuine pigments.

Fig. 5. Time behavior of fluorescence of red colours at peak wavelength under $\mathrm{Ar}^{+}$ion 
laser excitation $(\lambda=514.5 \mathrm{~nm})$. Peak intensities are normalized.

1: cadmium red $(590 \mathrm{~nm})$,

2: vermilion $(580 \mathrm{~nm})$,

3: scarlet lake $(620 \mathrm{~nm})$,

4: vermilion (tint) $(620 \mathrm{~nm})$,

5: carmine lake $(630 \mathrm{~nm})$,

6: laser light $(514.5 \mathrm{~nm})$.

Fig.6. Time behavior of fluorescence of carmine lake made by different manufacturers at peak wavelength under $\mathrm{Ar}^{+}$ion laser excitation. Peak intensities are normalized.

1: Matsuda,

2: Matsuda (super),

3: Asahi-Kusakabe,

4: Holbein.

Fig. 7. Fluorescence of yellow painting under $\mathrm{N}_{2}$ laser excitation. 
Table I. List of the characteristics of oil colours (white).

\begin{tabular}{cllcc}
\hline \multirow{2}{*}{ No. } & Name & Chemical formula & \multicolumn{2}{c}{ Fluorescence } \\
\cline { 3 - 5 } & & & Peak (nm) & Peak intensity (r. u. $)$ \\
\hline 1 & Zinc white & $\mathrm{ZnO}$ & 385 & 200 \\
2 & Titanium white & $\mathrm{TiO}_{2}$ & 381 & 4 \\
3 & Lead white & $2 \mathrm{PbCO}_{3} \cdot \mathrm{Pb}(\mathrm{OH})_{2}$ & - & $\leq 0.001$ \\
\hline
\end{tabular}


Table II. List of the characteristics of oil colours (yellow).

Fluorescence

\begin{tabular}{|c|c|c|c|c|}
\hline No. & Name & Chemical formula & Peak (nm) & $\begin{array}{l}\text { Peak intensity } \\
\text { (r. u.) }\end{array}$ \\
\hline 1 & Cadmium yellow & $\mathrm{CdS}$ & 520 & 1.4 \\
\hline \multirow[t]{2}{*}{2} & Lemon yellow & $\mathrm{BaCrO}_{4}$ & 520 & 0.05 \\
\hline & & & 383 & 130 \\
\hline \multirow[t]{2}{*}{3} & Citron yellow & $\mathrm{ZnCrO}_{4} \cdot \mathrm{K}_{2} \mathrm{CrO}_{4} \cdot \mathrm{ZnO}$ & 520 & 0.01 \\
\hline & & & 380 & 10 \\
\hline 4 & Chrome yellow citron & $\mathrm{PbCrO}_{4} \cdot \mathrm{PbSO}_{4}$ & 540 & 0.1 \\
\hline \multirow[t]{2}{*}{5} & Permanent yellow & Or. (Hansa y.) & 550 & 0.07 \\
\hline & & & 382 & 40 \\
\hline 6 & Aureolin & $\mathrm{K}_{3} \mathrm{Co}\left(\mathrm{NO}_{2}\right)_{6} \cdot 3 \mathrm{H}_{2} \mathrm{O}$ & 550 & 0.004 \\
\hline 7 & Chrome yellow light & $\mathrm{PbCrO}_{4} \cdot \mathrm{PbO}$ & 580 & 0.004 \\
\hline
\end{tabular}

Or.: organic compound. 
Table III. List of the characteristics of oil colours (red).

\begin{tabular}{cllcc}
\hline \multirow{2}{*}{ No. } & Name & Chemical formula & \multicolumn{2}{c}{ Fluorescence } \\
\cline { 4 - 5 } & & & Peak (nm) & Peak intensity (r. u.) \\
\hline 1 & Cadmium red & $\mathrm{Cd}(\mathrm{S}, \mathrm{Se})$ & 600 & 1 \\
2 & Vermilion & $\mathrm{HgS}$ & 600 & 0.14 \\
3 & Scarlet lake & Or. & 630 & 0.07 \\
4 & Vermilion (tint) & Or. & 640 & 0.04 \\
5 & Carmine lake & Or. & 640 & 0.2 \\
\hline
\end{tabular}


Fig. 1

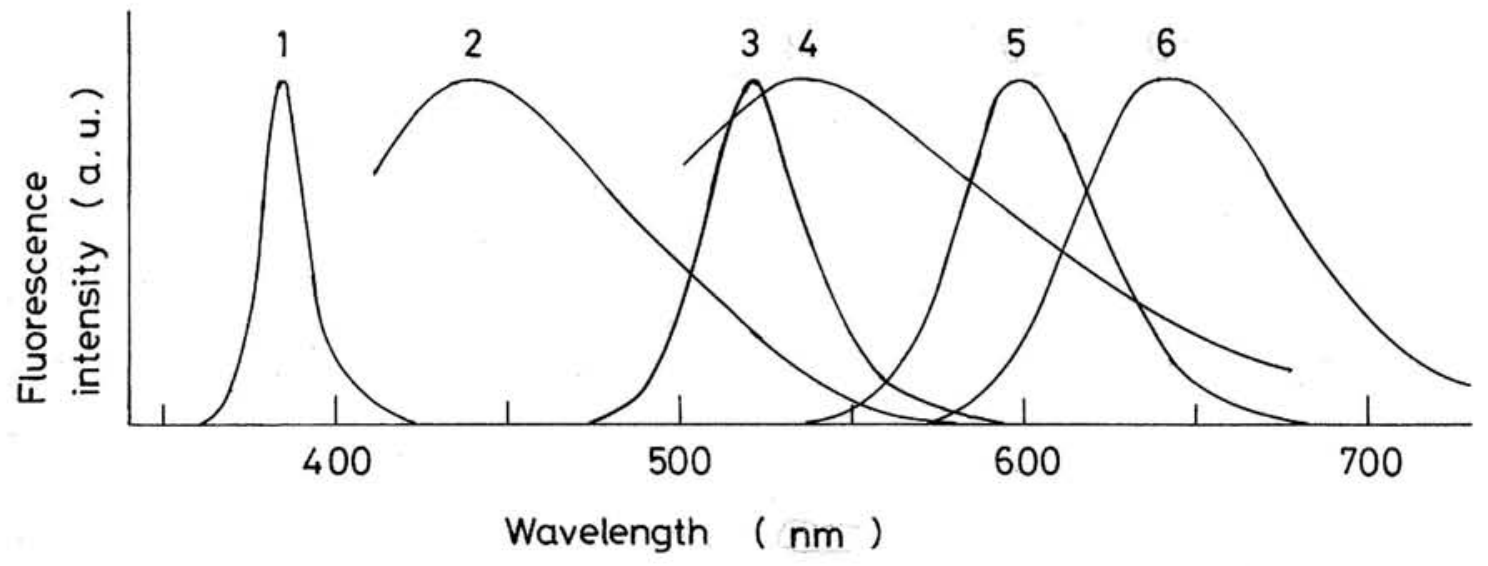

Fig. 2

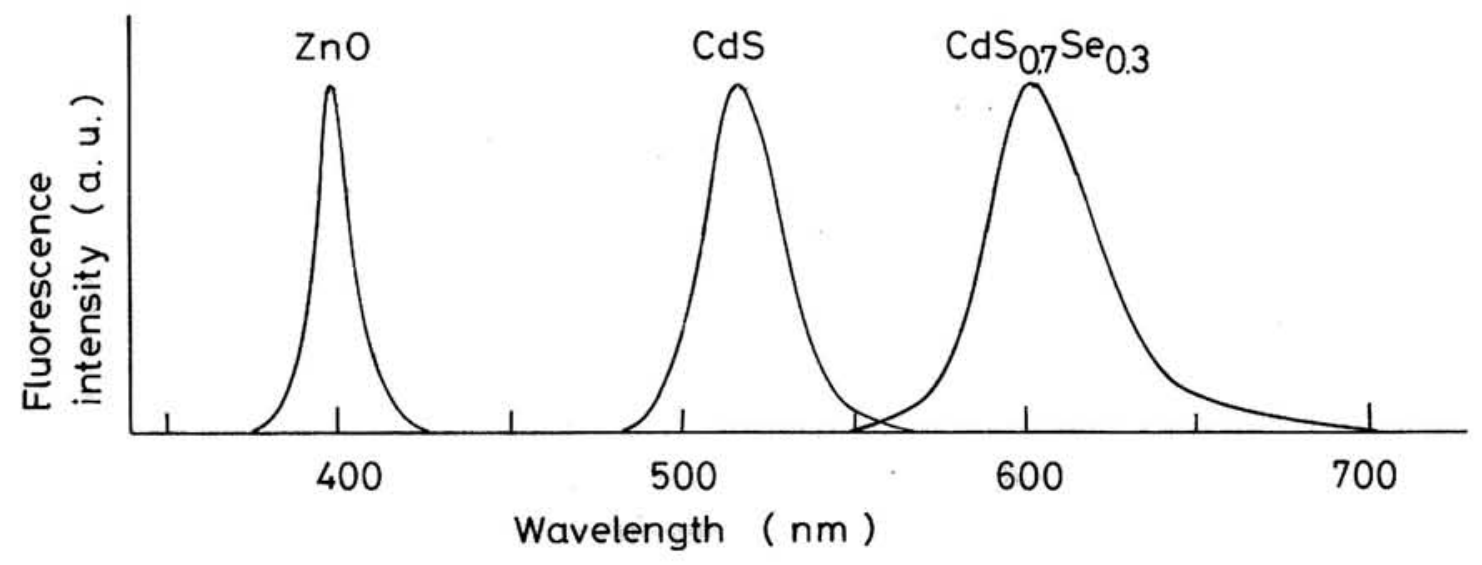


Fig. 3

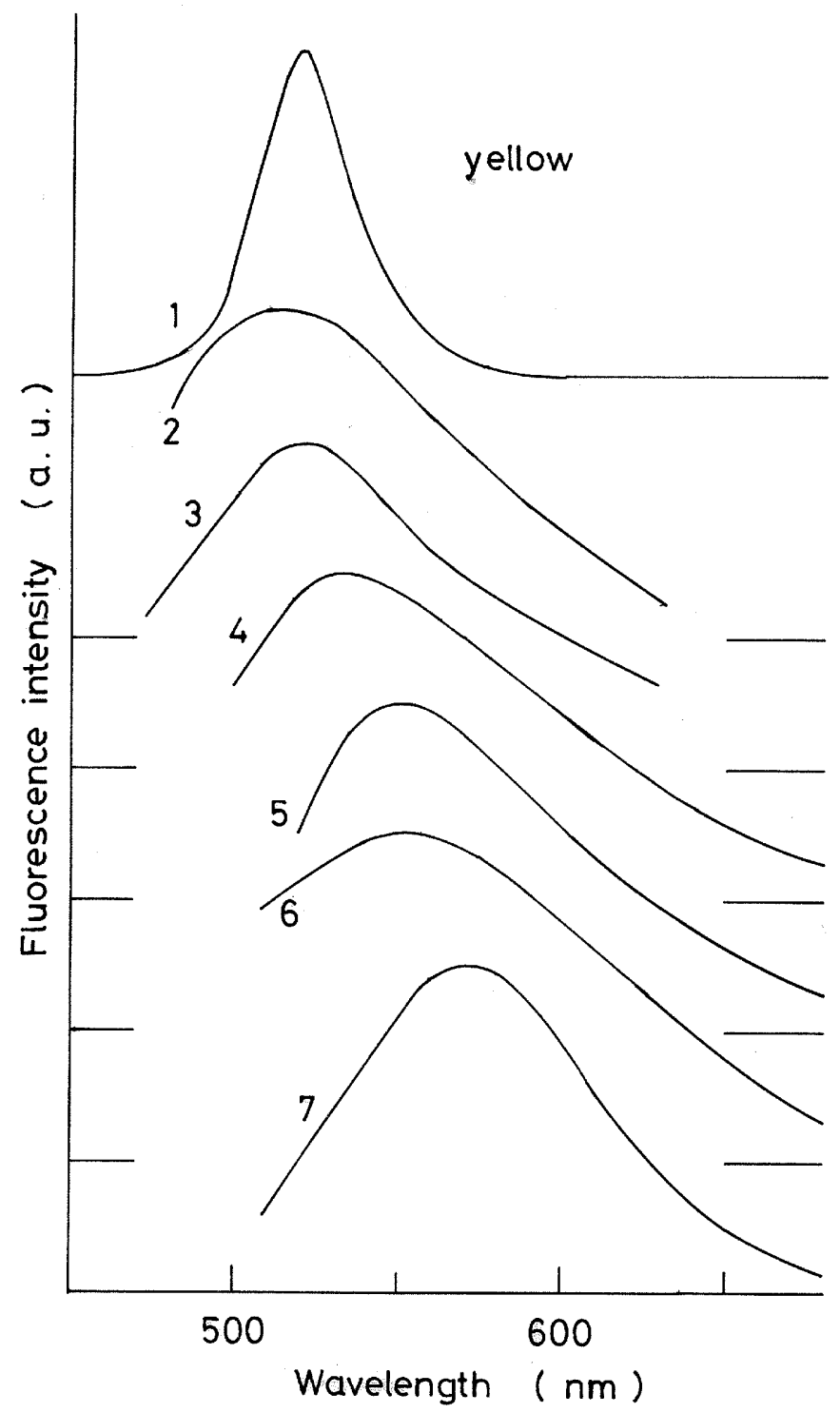

Fig. 4

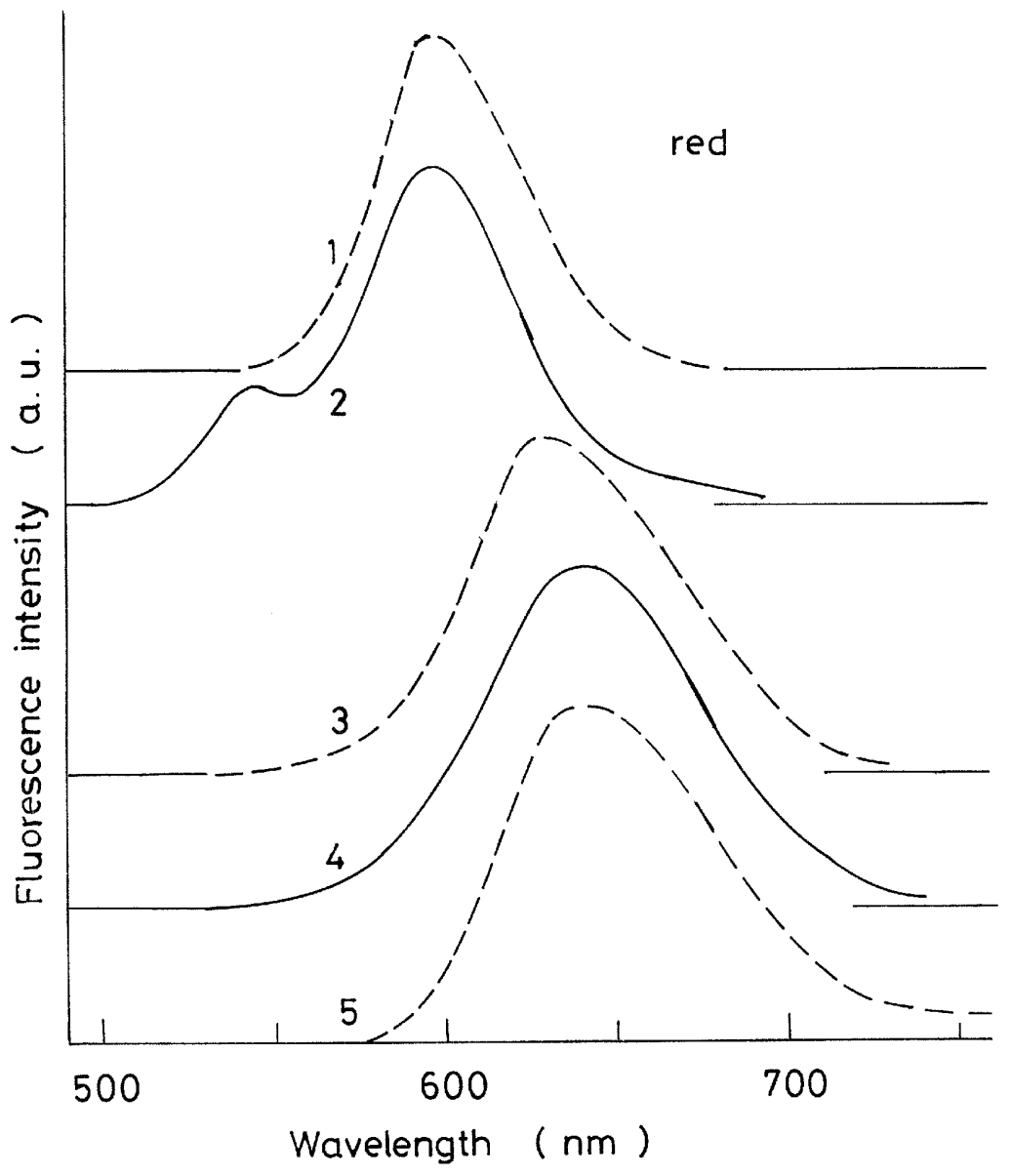


Fig. 5

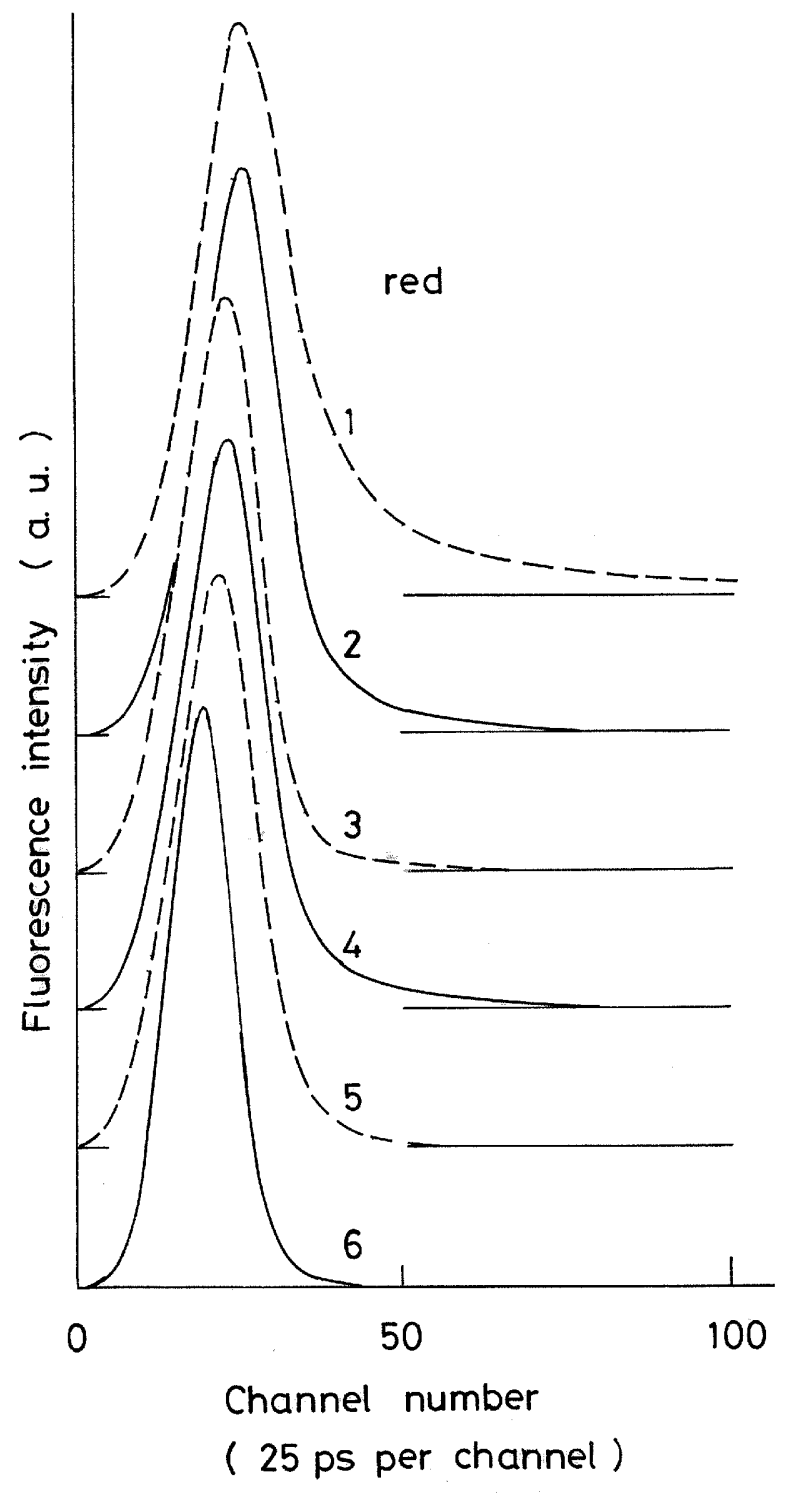


Fig. 6

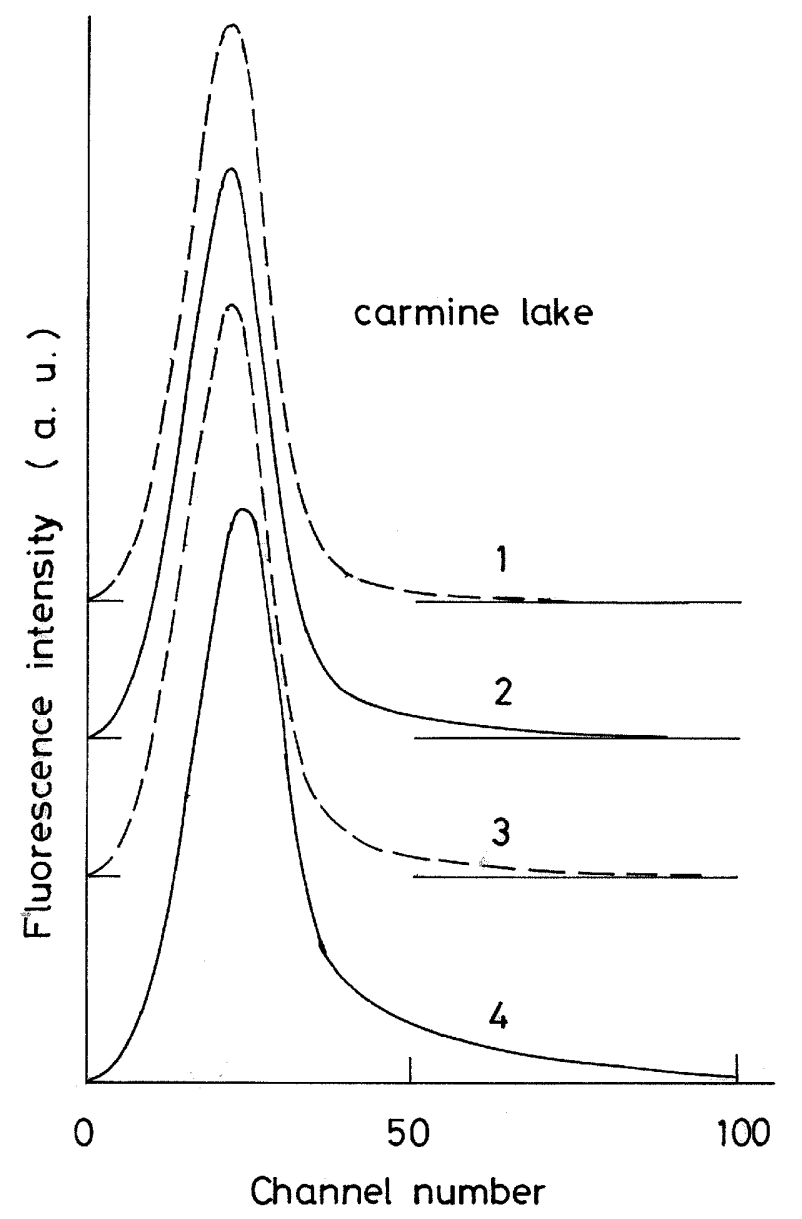

( 25 ps per channel)

Fig. 7

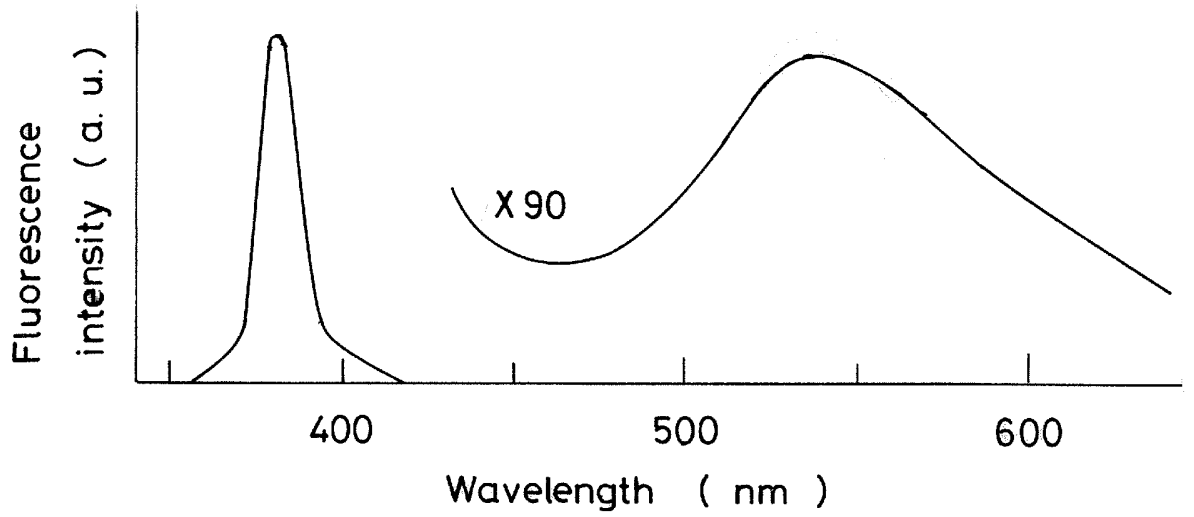

